\title{
Impact of Foreign Direct Investment on Economic Restructuring in Bac Ninh
}

\author{
Xuan Hung Nguyen* Thi Phuong Thuy Nguyen Thi Lan Nguyen Minh Hang Tang \\ Thi Nhung Nguyen \\ School of Trade and International Economics, National Economics University, 207 Giai Phong, Hai Ba Trung, \\ Ha Noi, Vietnam
}

\begin{abstract}
In recent years, foreign direct investment (FDI) has played an important role in Bac Ninh's economic restructuring. Of all provinces, Bac Ninh has always been leading the way for attracting foreign investment in Vietnam. The goal of this article is to study the relationship between FDI and the structure of economy of Bac Ninh. We use Ordinary Least Squares regression (OLS) to analyze the influence of the province's FDI on its economic restructuring over the period from 2009 to 2019 . The result partly shows that the FDI has had a strong impact on Bac Ninh's economic restructuring in both speed and quality. Through these findings, we propose several recommendations for the local authorities to continue to attract the FDI and reinforce the positive impacts of the FDI on the province's economic restructuring in the future.
\end{abstract}

Keywords: Bac Ninh, foreign direct investment (FDI), economic restructuring, OLS

DOI: $10.7176 / \mathrm{EJBM} / 12-15-03$

Publication date:May $31^{\text {st }} 2020$

\section{Introduction}

In the contemporary world, the trend in globalisation has developed more and more strongly than ever before, the fact that if a country wants to grow rapidly, building an open economy and taking advantage of foreign resources are indispensable. Since becoming an official member of WTO, Vietnam has committed to the openness of service market, which leads to the wave of foreign direct investment (FDI) into different economic sectors. This investment has made a lot of great breakthroughs to Vietnamese economy, especially its role in the transition of the economy into industrialization and modernizationstatus.

Bac Ninh, since re-establishment, has attracted a great amount of foreign direct investment from years to years due to many opening up policies and integration into the global economy. FDI play an important role in the formation of key industry, creating new careers and magnifying the technological leverage which all contribute to the increase of Bac Ninh's economic productivity. FDI mostly focuses on the industry, particularly processing industry, which make the careers of this field grow promptly, compared with these of other fields. Consequently, it can emerge some risks such as creating unsustainable economicstructure and causing an imbalance in the occupational structure of the province. To ascertain whether foreign direct investment has an impact on the economic restructuring in Bac Ninh or not and how does its effect, we need to have a more specific research.

The main objective of the article is to study the impacts of FDI on economic restructuring in Bac Ninh. The authors choose to use quantitative analysis, combined with descriptive statistics, comparable method, analysis, synthesis and ordinary least square (OLS) regressions to examine the influence of FDI on Bac Ninh's economic restructuring. Based on that, we propose some petitions for the local authorities to continue to attract foreign investment and to enhance the impacts of FDI on the province's economic restructuring in the future.

\section{Literature review}

There are several studies having been done on FDI and economic growth. Their findings vary from different methods used on their research and study different aspects of the economy, some researches concentrated on bringing conclusions about the role, essence and the impact of FDI on the economy, some others focused on specifically examining its impacts on a wide range of aspects in every nation, every region.

In the world, many of the researchers have done a variety of studies about the relationship between FDI and the economic restructuring. Blomstrom et al. (2000) examined how inward and outward FDI influenced the restructuring of the Japanese economyand can be expected to continue to do so in the future, they drew a conclusion that outward FDI was still not very large relativeto the Japanese economycompared to inward one. In 2008, Campos and Kinoshita investigated the role of structural reforms -financial reforms, trade liberalization,and privatization- as determinants of FDI inflows based on newly constructed dataset onstructural reforms Latin American and Eastern European countries between 1989and 2004, theyfound a stronger effect from financial sector reforms and privatization than from trade liberalization. In 2016, Jude and Silaghiexamined the role of FDI as a determinant of employment by using a dynamic labor demand model applied for Central and Eastern European countries, the research showed that FDI inflows did affect the problem of labor force and economic structure in some countries. 
However, some researchers investigated that FDI had little influence on the economic sectors in the long-run. For example, Djokoto (2013) examined the relationship between openness and agricultural performance and concluded that there was no long-run relationship between FDI and trade openness on the one hand, and agricultural performance on the other hand. However, in the short run, trade openness and FDI exerted a statistically significant negative effect on agricultural performance. This result provides an incentive for the reexamination of the type of FDI attracted into the agricultural sectors.

In Vietnam, there are also a lot of researches that have been done related to the FDI's effect on the economy. For instance, Nguyen Tien Long (2011) studied about the influence of FDI on the economic restructuring in Thai Nguyen, the result showed that FDI had a positive impact on the province's restructuring in the research phase. Nguyen Thi Mo also had the same research with the former one in 2011, but she focused on a larger scope which was FDI effects on the economic structure of Vietnam. A group of authors including Ho et al. in early 2020, studied about the impact of FDI on the environment in Vietnam, they presented that applying innovative technologies helped reduce environmental pollution.

Beside the positive influences FDI has brought, if there are no tightly controls, it can lead to wrong direction in the economic development strategy of every region. The research of Pham Duc Minh in 2016 about attracting FDI in northern major economic development area, he displayed the FDI's role in production efficiency, government revenue, work experience for the labor force, etc. However, the drawbacks of this capital was to creating imbalance in attracting FDI, providing a wrong direction in economic structure which led to the decline in the region's development.

Although there have been a wide range of researches related to FDI, there is not a plethora of adequate and systematic researcheson the causal relationship between FDI and economic restructuring in Bac Ninh and the ones that do exist are not clear: they do not give a definite causal result, while there have been a growing number of FDI projects in the province such as VSIP industrial park, Que Vo industrial park, Yen Phong industrial park and the strong activity of multinational corporations like Samsung, Nokia, etc. The researches listed above have brought lots of scientific values, from which the authors can inherit and contribute to the building of theoretical framework.

\subsection{Theoretical framework}

\subsubsection{Foreign direct investment}

According to The International Monetary Fund (IMF), foreign direct investment (FDI) is defined as a category of international investment that reflects the objective of a resident in one economy (the direct investor) obtaining a lasting interest in an enterprise resident in another economy (the direct investment enterprise). The lasting interest implies the existence of a long-term relationship between the direct investor and the direct investment enterprise, and a significant degree of influence by the investor on the management of the enterprise.

The United Nations Conference on Trade and Development defines FDI as an investment involving a longterm relationship and reflecting a lasting interest and control by a resident entity in one economy (foreign direct investor or parent enterprise) in an enterprise resident in an economy other than that of the foreign direct investor (FDI enterprise or affiliate enterprise or foreign affiliate). FDI implies that the investor exerts a significant degree of influence on the management of the enterprise resident in the other economy. Such investment involves both the initial transaction between the two entities and all subsequent transactions between them and among foreign affiliates, both incorporated and unincorporated."

However, it is possible to perceive that the nature of FDI is a category of international investment in which the country of investor (the invest country) invests in the country receiving investment (the host country) in order to take theownership of business objects in the host country, manage and keep control of them, thereby helping the invest countryget benefits.

\subsubsection{Economic restructuring}

Nowadays, there are multiple definitions of economic structure but in general, they all demonstrate that the economic structure reflects the nature of the economy whichis constituted ofdifferent parts with strong correlation and having certain contribution. It can be seen that economic structure is a category that covers many parts of the economy such as economic component, economic activity, economic sector, economic region... and the correlations among them.

The economic structure by sector is the division of the economy into groups of sectors and the overall relationship of them, it reflects the level of division of labor and the development level of the workforce in the economy. Therefore, the authors choose the economic structure by sector as well as the economic restructuring by sector as the assessment content of the economic growth.

The economic restructuring by sector is a change in the proportion of economic sectors in the economic structure from one state to another in order to implement the economic development goals.

\subsubsection{The relationship between FDI and economic restructuring in the host country}

Economic restructuring is required for most countries in the process of development nowadays. The economic 
restructuring of a country requires the transfer of each local economic structure. With FDI, countries can penetrate deeper into international markets, when entering international market, it is necessary for the localities to change their economic structure to a more suitable one.

FDI plays a very important role in the local economic restructuring as it generates new industries, rapidly enhances the level of technology, which contribute to the increase in economic productivity. FDI mainly concentrates on industries and services, make these sectors grow rapidly, especially in the processing industry, which outweigh other sectors of agriculture.

However, sectors and positions having been invested depend a lots on foreign investors, sometimes, they don't rely on the countries receiving investment. Moreover, it also causes risks and leads to unsustainable economic structure, imbalance in structure of economic sectors, occupations and territories. Technical infrastructure of industrial parks and free-trade zones is in highquality but there is a shortage of skilled labor. The fact that provinces focus too much on technical infrastructure to attract investment without creating a synchronization in social and cultural infrastructure also limits the impact of FDI on economic restructuring. The lack of synchronization in creating elements to carry out projects in the provinces is also a cause of limiting the implementation of projects, limiting the contribution of FDI.

\section{Research Methods}

\subsection{Methods of collecting data}

This study employed data gathered and aggregated from the previous researches, data from General Statistics Office of Bac Ninh including Bac Ninh Statistical Yearbook over the periods 2014 to 2018; economic and social report in 2018 and 2019. Foreign direct investment report in Bac Ninh quarterlyover the periods 2009 to 2019 from Bac Ninh Department of Planning and Investment.

In this research, the authors utilize annual data span from 2009 to 2019 including 11 observations.

\subsection{Data processing}

This research used quantitative and qualitative methods. First of all, in order to evaluate the switch in the sectoral economic structure, it is necessary to use evaluation criteria which is the level of the switch in economic structure calculated by the following formula:

In which:

$$
\cos \varphi=\frac{\Sigma S_{i}\left(t_{2}\right) S_{i}\left(t_{1}\right)}{\sqrt{\Sigma S_{i}^{2}\left(t_{2}\right) \Sigma S_{i}^{2}\left(t_{1}\right)}}
$$

$\mathrm{S}_{\mathrm{i}}(\mathrm{t})$ is the proportion of sector I in GDP year $\mathrm{t}$

$\varphi$ is the angle between two economic structure vectors

If $\varphi=0^{\circ}$ (or $\left.\cos \varphi=1\right)$, there is no switch in economic structure.

If $\varphi=90^{\circ}$ (or $\left.\cos \varphi=0\right)$, the switch is relative.

With the remaining values $\left(0^{\circ}<\varphi<90^{\circ}\right)$, there is switch in economic structure.

By using the OLS method of estimation, the authors did correlation regression between FDI growth and the switch in economic structure by model:

$$
\mathbf{Y}_{t}=\boldsymbol{\beta}_{1}+\boldsymbol{\beta}_{2} \mathbf{X}_{\mathbf{t}}+\mathbf{u}_{\mathrm{t}}
$$

In addition to evaluating how the increase or decrease of FDI impact on the level of structural change, we can also consider how FDI has an impact on the structure of each sector in the economy.

Select research variables and scales:

$\mathrm{Xt}$ is the level of FDI growth, for the years in which FDI decreased compared to the previous year, the growth is supposed to be zero.

$\mathrm{Y}=(\varphi$,Proportion of sectors in the economy)

- When $Y_{t}$ is the level of the switch in economic structure year $t$, measured by $\varphi$. After calculating the level of structural shift $\cos \varphi$, we can convert it into $\varphi$ to see how much the change of the angle is, thereby evaluating the rate of the switch.

- When $Y_{t}$ is the proportion of sectors in the economy, $Y_{t}$ is calculated as the percentage of each argo - forestry, industry and services branch in the province's GDP.

Form of the research model:

$$
\begin{gathered}
\varphi_{t}=\beta_{1}+\beta_{2} g_{F D I}+u_{t-1} \\
\text { And } C C N_{t}=\beta_{1}+\beta_{2} \text { FDI }_{t-1}+u_{t}
\end{gathered}
$$

\section{Results and discussion}

In order to measure the level of economic structure switch, the authors used the $\cos \varphi$ coefficient as mentioned above. Calculation results of the shifting angle and the growth of implemented FDI capital resources are shown in table 1 . 
Table 1: The speed of sector structure shift in Bac Ninh from 2009 to 2019

\begin{tabular}{|c|c|c|c|c|c|c|}
\hline \multirow{2}{*}{ Year } & \multicolumn{2}{|c|}{ Proportion in GRDP (\%) } & \multirow{2}{*}{ Cos $\boldsymbol{\varphi}$} & \multirow{2}{*}{$\begin{array}{c}\text { GFDI } \\
\text { (\%) }\end{array}$} \\
\cline { 2 - 5 } & Argriculture & $\begin{array}{c}\text { Industry - } \\
\text { Construction }\end{array}$ & Services & & & 0.00 \\
\hline 2009 & 12.44 & 63.74 & 23.82 & 0.99940533 & $1.976032^{\circ}$ & 0.00 \\
\hline 2010 & 10.45 & 62.48 & 27.07 & 0.99831808 & $3.323533^{\circ}$ & 39.22 \\
\hline 2011 & 10.06 & 66.35 & 23.59 & 0.99773467 & $3.857312^{\circ}$ & 24.34 \\
\hline 2012 & 8.01 & 68.68 & 23.31 & 0.99938906 & $2.002889^{\circ}$ & 118.36 \\
\hline 2013 & 4.24 & 78.12 & 17.64 & 0.99289129 & $6.835816^{\circ}$ & 43.74 \\
\hline 2014 & 4.20 & 74.19 & 21.61 & 0.99812278 & $3.511259^{\circ}$ & 0.00 \\
\hline 2015 & 4.01 & 73.55 & 22.44 & 0.99991728 & $0.736951^{\circ}$ & 41.01 \\
\hline 2016 & 3.65 & 72.23 & 24.12 & 0.99964979 & $1.516403^{\circ}$ & 25.40 \\
\hline 2017 & 2.93 & 74.39 & 22.68 & 0.99960076 & $1.619078^{\circ}$ & 107.45 \\
\hline 2018 & 2.89 & 76.75 & 20.36 & 0.99932884 & $2.099302^{\circ}$ & 0.00 \\
\hline 2019 & 2.64 & 75.72 & 21.64 & 0.99981423 & $1.104391^{\circ}$ & 0.00 \\
\hline
\end{tabular}

Source: Bac Ninh's Statistical Yearbook and the authors' calculation

Since 2009, Bac Ninh's economic structure has been quite in line with the country's industrialization and modernization trend. The proportion of agriculture was the lowest, corresponding to $12.44 \%$, the proportion of industry - construction was the highest, accounting for $63.74 \%$. In 2013 , the proportion of agriculture decreased significantly, at only $4.24 \%$, the proportion of industry - construction increased rapidly at $78.12 \%$ and maintained at the highest peak. In 2013, it was also recorded a shift angle of $6^{\circ} 50^{\prime}$ - the highest shift angle in the period of 2009 - 2019 which showed a rapid economic structure switch. The reason for that is because FDI increased by more than 118\%in 2012, mainly thanks to the contribution of the project of Samsung Electronics Vietnam Co., Ltd. in Bac Ninh Industrial Park, with a registered capital of 830 million USD.

To test whether FDI has an impact on economic restructuring or not, the authors used correlation regression between the growth rate of FDI and the economic restructuring. At the same time, the authors used correlation regression betweenthe value of FDI and the proportion of agriculture, industry - construction and service industry to estimate the impact of FDI on the proportion of these sectors. The estimated results are summarized in the table below.

Table 2: Results of estimating the impact of FDI on economic structure shift

\begin{tabular}{|c|c|c|c|c|}
\hline $\begin{array}{c}\text { Dependent } \\
\text { variables }\end{array}$ & $\begin{array}{c}\text { Independent } \\
\text { variables }\end{array}$ & $\beta_{2}$ & Prob. & $\begin{array}{c}\text { Adjustment } \\
\text { factor }\end{array}$ \\
\hline$\varphi$ & GFDI (-1) & 2.684899 & 0.0525 & 0.392840 \\
\hline NN & FDI (-1) & -0.0000188 & 0.0156 & 0.538989 \\
\hline CN & FDI (-1) & 0.0000274 & 0.0407 & 0.426161 \\
\hline DV & FDI (-1) & -0.0000086 & 0.2397 & 0.167843 \\
\hline
\end{tabular}

Source: Results from Eviews

Firstly, the model to estimate the impact of FDI on economic restructuring, $p$-value $=0.0525$ shows that $\beta_{2}$ is significant at $10 \%$, the coefficient with positive sign $(+)$ proves that FDI has a positive effect on economic restructuring's speed. $\beta_{2}=2.684899$ describes that when the growth rate of FDI increases by 1 unit (correspond to $100 \%$ ), the shift angle of the following year increases by approximately $2^{\circ} 41^{\prime}$. Adjustment factor indicates that the growth rate of FDI explains $39.3 \%$ of the change of the economic restructuring angle.

For more detailed assessment, the impact of FDI on each sector is estimated:

Argriculture sector:

$\mathrm{P}$-value $=0.0156$ shows that $\beta 2$ is significant at $5 \%$.

The negative sign (-) indicates that the increase of FDI reduces the proportion of agriculture. The reason is that FDI mainly invested in industry increases the proportion of industry - construction, leading to a decrease in the proportion of agriculture.

The adjustment factor of the model shows that almost $54 \%$ of the variation in the proportion of agriculture is explained by FDI.

\section{Industry sector:}

$\mathrm{P}$-value $=0.0407$ shows that $\beta 2$ is significant at $5 \%$.

The positive sign $(+)$ indicates that FDI has a positive impact on the proportion of industry - construction. The rate of FDI investment in industry is always very high, which increases the proportion of industry in particular and industry - construction in general.

The adjustment factor indicates that $42.6 \%$ of the fluctuation of the proportion of industry - construction is caused by FDI. 


\section{Services sector:}

P-value $=0.2397$ shows that the model is not statistically significant,in other words, FDI has no impact on the proportion of the services sector of the province.

Consequently, FDI has a positive effect on the economic restructuring and the proportion of industry - construction of the province. Industrial production received a large investment from FDI which directly increased the proportion of industry - construction, thereby indirectly reducing the proportion of agriculture. However, FDI has not affected the proportion of the service sector - the sector is believed to have rapid growth in the future.

\section{Conclusion}

The article attempt toprovide a longitudinal study of the causal link between FDI and economic restructuring in Bac Ninh. Though the results are approximate due to the limited data, the authors can still draw some conclusions through the analyses from the ordinary least square (OLS) regressions and propose some petitions for the local authorities and the government to continue to attract foreign direct investment in Bac Ninh in the future. By analyzing the empirical result from the OLS regressions, the authors reach some specific conclusions:

The result of the study reveals thatFDI performance index in the province is unstable and reflects the world economic's fluctuations, which create the issue of how to attract sustainable FDI for the province. Moreover, Bac Ninh economy is restructuring at an uneven speed throughout the years due to different reasons, and FDI holds a considerable proportion.

Furthermore, the growth in FDI capital has a strong impact on the province's economic restructuring. About $40 \%$ of the restructuring of the economy depends on the increasing number of foreign direct investments. The economy is restructuring in a positive way.Agriculture's contribution to gross regional domestic product (GRDP) has dropped significantly since 2009, whereas the percentage of industry and construction have rapidly increased throughout the years. Besides, the changes in the number of FDI in the province,which mainly depends on the world economy, can lead to a decline in the economic restructuring's rate.

On the one hand, FDI exerted a statistically significant negative effect on the agriculture of Bac Ninh. The increasing of FDI describes more than $50 \%$ of the decline in agricultural percentage in the GRDP growth. Nevertheless, the important role of agriculture in the economic growth is undeniable, as a result, it requires more attention from the local authorities to develop into green agriculture, which is the trend of most countries in the world.

On the other hand, FDI contributes to the growth of industry and construction, especially industry, in a positive way. FDI explains more than $40 \%$ of the fluctuations in the industrial and constructional structure. The growing amount of FDI inflow is proved to boost the industrial and constructional performance of not only that year but also the following years and vice versa.

Bac Ninh service industry arouse little attention from the foreign direct investors, despite its key role in accelerating economic growth. The empirical result shows that FDI has little effect on the development of service industry in Bac Ninh.

As can be seen from the above results, FDI has a considerable effect on the economic restructuring in Bac Ninh. Investing a large amount of foreign capital to the industrialsector directly contribute to the industrial performance, however, indirectly affect the agriculture in a negative way. FDI has not much influence on the service industry - the sector is believed to have the potential to develop and bring lots of economic value to the global economy. It can be concluded that foreign direct investors are mostly concentrating on the industrial sector instead of others, it is mainly because of the lack in the policies to attract foreign investors. Bac Ninh should find solutions to continue to attract FDI into more economic sectors of the province. Also, the great dependence of the capital on the foreign investors can lead to lots of adverse effects, especially in the unstable economy of the world. Therefore, the province need to promote its available resources to facilitate foreign investors in boosting economic restructuring.

\section{Solutions}

Through the empirical results, the authors propose some petitions for the local authorities to continue to attract foreign direct investment and to enhance the impacts of FDI on the province's economic restructuring in a positive way.

Firsly, enhance the quality of foreign direct investment as well as stimulate the economic restructuring in Bac Ninh economic development strategy in the future.

Define scope for foreign direct investment and domestic investment to facilitate the process of calling for investment in the province. Precisely evaluate the potentials and demands of Bac Ninh's markets, from which the local authority enact more projects to call for FDI, the information should be made public on the web portal of the province.

Expand the investment field for FDI. The fact that real estate has achieved a great deal of foreign capital while the service industry depends much on domestic capital goes against the trend of the world economy. In recent years, 
the world service industry is proved to have attracted a growing amount of FDI inflow. As a result, beside industrial sector, the province should also orient to calling for investment into different sectors such as agriculture and services.

\section{Secondly, facilitate the process of attracting FDI to the province's priority economic sectors}

Increasing the proportion of the industry using up-to-date technology and the service industry is the current trend of economic restructuring in the world. To catch on the international trend, Bac Ninh should have separated policies for every economic sector

\section{Industry}

Complete the planning to improve supporting industries to create resources for the FDI enterprises, the People's committee of Bac Ninh should establish an office including skilled staffs to keep track of the activities of economic sectors. Encourage the foreign enterprises to invest in supporting industries. The government supports them with preferential policies about land price, infrastructure cost, interconnected transport infrastructure, etc.

Train more skilled labor for supporting industries, assist them with knowledge about advanced technology, provide the province's universities, vocational schools with training programs affiliated to reputable universities, vocational schools worldwide. There is also a need to improve educational facilities from the universities to vocational schools with the aim of improving the quality of labor force.

\section{Agriculture}

Prioritize the FDI projects that concentrate on bringing agricultural products to the world, encourage FDI projects having criteria of using high technology, environmental friendliness, having high budget and using little land, little labor force.

Approach intelligent agriculture, call for FDI in investing into modern equipment to serve agricultural sectors. Investing and creating more projects, smart farming models in rural areas of Bac Ninh. The province has currently had some projects utilizing advanced technology in farming and herding, which has helped form lots of specialised farmings, bring lots of economic value. Besides, there have been a growing number of projects applying high technology to aquaculture. All of which have set the stage for encouraging FDI enterprises to invest in agriculture. Services

Enhance the service industry's growth, continue to use the capital from national budget, foreign and domestic enterprisesto build infrastructure for tourism industry, entertainment services of the province. Furthermore, improve the infrastructure can create environment like restaurants, hotels, transportfor the investors to live and work in the region ofprovince. Support the process of exporting products of FDI enterprises.

\section{Thirdly, create attractive environment, invest in education, train skilled labor force to encourage FDI}

Upgrade the province's infrastructure, utilize the capital from national budget, ODA capital, government debt to syncthe infrastructure such as waste water treatment station, fundamental facilities in educational institutions, vocational schools, especially in the industrial parks.

Improve the quality of labor force, the province should propose some policies to attract more skilled labor, increase investment in vocational schools, launch more propagandacampaigns to encourage people who cannot afford to go to the universities can have chance to study skills required for a specific job. Bac Ninh should not only focus on capacity building but also pay attention to improving the worker's health, periodically check the Food safety, support the business enterprises to provide nutritional diet for the workers in the industrial parks.

The province should propose some policies for the FDI enterprises, before investing in the province, should assure the benefits of not only the province but also of Vietnam. Ensure to comply with the environmental law, not to affect the local's lives, the activities of the enterprises should abide by Vietnam's laws and the province's regulations and have to pass the entry test of the province's committee.

\section{Fourthly, receive investment selectively and keep close control of FDI capital}

Provide a careful selection of FDI capital, focus on examining its impacts on the environment, apply a censorship before the practice of licensing to the foreign enterprises. This process need to include a close coordination of the Departments, Boards of the province. Restrict investment from the investors who invest in the sectors that may do harm to the environment, small investors with low budget or the investors from the regions that are not suitable with the nation's orientation.

Keep control of the activities of FDI enterprises frequently, especially the process of manufacturing, building infrastructure, building factories. Produce strong security measures for the projects that have adverse effects on the environment or break the laws of the province. The activities of sewage treatment stations in the industrial parks should be put under surveillance. FDI enterprises must inform long-term planning for waste treatment from the beginning.

Fifthly, inform some preferences to attract FDI but have to make sure to create a level playing field in order to give opportunities to the domestic producers to become a part and enjoy the profit together with foreign direct investors

Keep the information about the preferences for the investors clear and up to date. Propose policies to publicize preferential policies, necessary information for foreign investors on the web portal of Bac Ninh, Bac Ninh 
Department of Planning and Investment, Department of Industry.

Facilitate the output for FDI projects, provide greater support for export process of the business enterprise, finding the consumer's market for the enterprises. Enhance the support work, facilitate the process of implementation of investment projects.

Conduct reforming administrative procedures, accelerate the processing time for records for the investment registration activities as well as the export process of FDI enterprises.

\section{Sixthly, utilize the FDI capital effectively and avoid depending too much on this capital}

Balance the use of FDI inflows, if the economy rely too much on FDI, it can easily lead to the "hot" growth and unsustainable condition. Moreover, the exporting industry can be badly affected if there is an economic crisis in the world, since most multinational companies are heavily influenced by the world economy. The province should keep control of creating plans and clarify the goals for the Local Department, Boards.

Besides, to improve FDI capital sustainably, the government should supplement and complete Vietnam's legal documents related to the investor when investing in the provinces, to avoid the situation of the employers abusing legal loopholes to withdraw investment. For the local committee, the related Department and Boards should co-ordinate to deal with the violation of law situations, along with finding solutions to attract more FDI to a variety of economic sectors.

\section{References}

C. Jude \& MIP Silaghi (2016), 'Employment effects of foreign direct investment: New evidence from Central and Eastern European countries', International Economics, C(145), 32-49.

Djokoto, G. J. (2013), 'Openness and agricultural performance in Ghana',Journal of Science and Technology, 33(2), 24-36.

General Statistics Office of Bac Ninh (2015 - 2019), Bac Ninh Statistical Yearbook annually, Bac Ninh.

General Statistics Office of Bac Ninh (2017), Bac Ninh Statistical Yearbook-Bac Ninh 20 years construction and development: 1997-2016, Bac Ninh.

General Statistics Office of Bac Ninh (2019), Socio-economic situation in 2018, Bac Ninh.

General Statistics Office of Bac Ninh (2020), Socio-economic situation in 2019, Bac Ninh.

Ho,D.B.,Dinh,D.T., Nguyen, P.H.\& Pham, T.P. (2020), 'Impacts of foreign direct investment on the environment in Vietnam', Journal of Economics and Development, 273, 2-32.

Magnus Blomstrom, Denise Konan \& Robert E. Lipsey (2000), 'FDI in the Restructuring of the Japanese Economy', The NBER Working Paper, 7693, DOI: 10.3386/w7693.

Nauro F. Campos \& Yuko Kinoshita (2008), 'Foreign Direct Investment and Structural Reforms: Evidence from Eastern Europe and Latin America', The IMF Working Paper, WP/08/26.

Nguyen, N.T. (2017), 'Economic restructuring in the city of Da Nang', Dissertation for MSc Development Economics, University of Economics - The University of Danang.

Nguyen, T.L. (2011), 'Impacts of foreign direct investment (FDI) on the economic restructuring in Thai Nguyen', Dissertation for MSc Economics, National Economic University.

Nguyen, T.M. (2011), 'Impacts of attracting foreign direct investment into economic restructuring in Vietnam', Dissertation for MSc Economics, VNU University of Economics and Business.

Pham,D.M. (2016), 'Attracting foreign direct investment into economic restructuring in the Northern key economic region, Dissertation for MSc Economics, Thai Nguyen University of Economics and Business Administration.

Tran, B.V. (2017), 'Impacts of foreign direct investment on the economic growth in Thai Nguyen', Dissertation for MSc Economics, National Economic University. 